\title{
Formation and development of supraglacial lakes in the percolation zone of the Greenland ice sheet
}

\author{
CHRISTINE CHEN, IAN M. HOWAT, SANTIAGO DE LA PEÑA \\ School of Earth Sciences and Byrd Polar and Climate Research Center, The Ohio State University, Columbus, OH, USA \\ Correspondence: Ian M. Howat<ihowat@gmail.com>
}

\begin{abstract}
We examine repeat surface altimetry and radio echo observations of two supraglacial lakes in the percolation zone of the Greenland ice sheet to investigate the changes in firn conditions leading to lake formation and implications for meltwater storage within firn. Both lakes formed in 2011, when an anomalously high melt season was followed by low winter accumulation, resulting in reduced infiltration and storage in the near surface. The lakes expanded during the 2012 record melt season and retained liquid meltwater through the following winter. The lakes then contracted, with one lake slowly draining and refreezing and another rapidly draining to the subsurface. The lack of observable change in firn conditions surrounding the lakes indicates increased run-off in the near surface firn, likely along low-permeability ice layers formed during the previous melt seasons. This implies a reduced ability of the firn to absorb increased meltwater.
\end{abstract}

KEYWORDS: glacier hydrology, polar firn, remote sensing

\section{INTRODUCTION}

Temperatures over the Greenland ice sheet have been increasing since the 1990s (Box, 2013), leading to an expansion of the percolation zone (e.g. Box, 2013; Van Angelen and others, 2014; De la Peña and others, 2015), where surface meltwater seasonally infiltrates the underlying snow and firn. Observations show that meltwater can penetrate deep within the firn, suggesting that the firn pore space may sequester a substantial amount of an increase in meltwater and thus act as a buffer between increasing melt, run-off and contribution to increased sea level. Based on observations from western Greenland, Harper and others (2012) estimate that the ice sheet's firn, from bare ice to the upper extent of melt, could absorb between 322 and 1289 gigatons of meltwater, or approximately the equivalent mass of 1-4 years of average run-off.

The mass of meltwater that the firn layer will retain, however, is determined by its porosity and the depth to which melt may penetrate. The permeability of firn, and how permeability changes as firn conditions change, is largely unknown. Harper and others (2012) found that deep penetration of meltwater between 1600 and $2000 \mathrm{~m}$ elevation in west Greenland was facilitated by cracks in thin ice layers and narrow, vertical 'pipes' along which water traveled through relatively low-density firn. Several anomalously intense melt seasons have resulted in substantial densification of the near surface firn and the formation of thick ice layers, reaching over $1 \mathrm{~m}$ thick (Machguth and others, 2016; Mikkelsen and others, 2016). This was concurrent with the inland expansion of surface meltwater lakes over the southwestern margin to elevations hundreds of meters above the equilibrium line and well into the percolation zone (Howat and others, 2013; Fitzpatrick and others, 2014). The expansion of lakes to higher elevations indicates increased lateral transport of meltwater, rather than vertical infiltration and storage at depth. The ability of the firn to absorb increases in meltwater may therefore be significantly limited by a concurrent increase in shallow firn density and reduction in its permeability. For example, intense melting, infiltration and refreezing in previous summers may create an effectively impenetrable ice layer that would act as an aquitard to meltwater generated in subsequent years.

The formation of new lakes at higher elevations in the percolation zone offers an opportunity to examine the changing hydraulic conditions of the firn under increased melt. We hypothesize that these lakes form due to a reduction in firn permeability at shallow depths, resulting in lateral transport of meltwater into topographic depressions. Therefore, the appearance of a lake indicates that the pore space at depth within the firn (i.e. below the base of the aquitard upon which the lake is perched) has become inaccessible to infiltration. If the lake is perched above the previous year's accumulation, it implies a nearly complete nullification of the firn's ability to absorb meltwater under warming at that elevation.

Here we examine repeat, airborne snow-penetrating radar and laser altimetry collected by the NASA's Operation IceBridge over two lakes that first appeared in the percolation zone of western Greenland during the summer of 2011. We use these observations to assess the conditions that caused the lakes to form and how the lakes evolved over subsequent years.

\section{DATA AND METHODS}

Our primary datasets for examining percolation zone lake evolution are surface elevation and near-surface radar transects obtained by the US National Aeronautics and Space Administration's Operation IceBridge (OIB) airborne surveys conducted each spring (March-May) between 2009 and 2015. In order to locate lakes that appear after 2009 and that were overflown annually by OIB along repeat trajectories, we created a database of sequential, melt season imagery from Landsat Enhanced Thematic Mapper Plus (ETM+), Landsat Optical Land Imager (OLI) and Advanced Spaceborne Thermal Emissivity and 
Reflection Radiometer (ASTER) for the margin of southwest Greenland. Orthorectified imagery were obtained online from the US Geological Survey. These images were used to locate lakes that formed above $1500 \mathrm{~m}$ after the year 2009, as documented in Howat and others (2013). Following lake detection, OIB flight lines are overlain on the imagery to determine if and how often the lake was surveyed. While we identify numerous recently formed lakes, we identify only two that appeared for the first time in the satellite imagery after 2009 and were surveyed each season between 2009 and 2015 (Fig. 1; Table 1). Lake 1 is located at $68^{\circ} 28^{\prime} 07^{\prime \prime}$ North, $314^{\circ} 49^{\prime} 46^{\prime \prime}$ East at 1780 m elevation. Lake 2 is located at $69^{\circ} 14^{\prime} 31^{\prime \prime}$ North, $313^{\circ} 08^{\prime} 48^{\prime \prime}$ East at $1722 \mathrm{~m}$ within the catchment of Jakobshavn Isbrae.

For each lake, we examine time series of snow surface elevation and near-surface firn structure obtained along the repeat OIB flight lines. Surface elevation is obtained from the Airborne Topographic Mapper (ATM) scanning lidar. We use the ATM Level 2 Elevation, Slope and Roughness, Version 2 product distributed by the National Snow and Ice Data Center. The Level 2 data are obtained from fitting overlapping planes to subsamples of the Level 1 point cloud. These planes span the lidar swath width evenly in one nadir and three off-nadir tracks. The planes are spaced approximately every $0.5 \mathrm{~s}$ in the along-track direction with $\sim 50 \%$ overlap (Krabill, 2010, updated, 2015). The ATM scanning lidar has a vertical accuracy of $10-20 \mathrm{~cm}$. The nadir block, whose center is beneath the aircraft centerline, is used for all 2011-15 ATM Level 2 elevations for Lake 1 and all ATM elevations for Lake 2 (2011-13, 2015) except

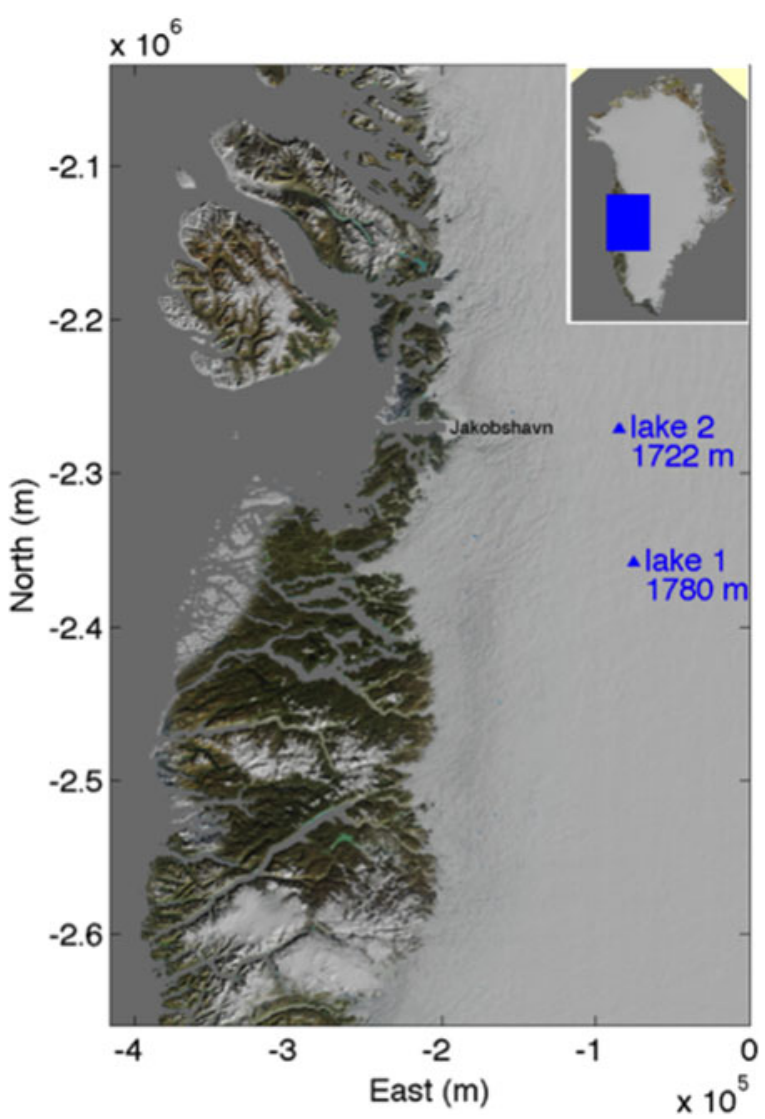

Fig. 1. Location and elevation, in m.a.s.I., of Lakes 1 and 2 on the western margin of the Greenland ice sheet. The projection is EPSG 3413 Polar Stereographic.
Table 1. Snow Radar details for the two lakes

\begin{tabular}{lcl}
\hline Date of survey & Segment \# & Frame \# \\
\hline Lake 1 & & \\
$04 / 06 / 2011$ & 02 & $632-633$ \\
$04 / 29 / 2012$ & 01 & $386-387$ \\
$04 / 04 / 2013$ & 04 & 004 \\
$04 / 09 / 2014$ & 01 & $573-574$ \\
$04 / 21 / 2015$ & 13 & $108-109$ \\
Lake 2 & & \\
$04 / 22 / 2011$ & 02 & 025 \\
$04 / 29 / 2012$ & 01 & $043-044$ \\
$04 / 06 / 2013$ & 03 & $339-340$ \\
$04 / 14 / 2014$ & 02 & 337 \\
$04 / 23 / 2015$ & 02 & \\
\hline
\end{tabular}

2014 (Fig. 1). Due to its proximity to the nadir track of previous years, an off-nadir track, track 2, is used in 2014 for Lake 2.

Changes in near-surface $(<20 \mathrm{~m}$ depth) firn structure are investigated using echograms obtained with the University of Kansas Snow Radar, an ultra-wideband Frequency Modulated Continuous Wave (FMCW) microwave $(2-8 \mathrm{GHz})$ imaging radar with a range resolution of $4.0 \mathrm{~cm}$ in snow (Leuschen and others, 2014; Rodriguez-Morales and others, 2014). We use the IceBridge Snow Radar L1B Geolocated Radar Echo Strength Profiles, Version 1 and 2 products from the National Snow and Ice Data Center (2009-13) and CReSIS (2014 and 2015). The vertical coordinates of the Snow Radar echograms were corrected by aligning the surface echo with the ATM-observed surface height, resulting in shifts of 1-2 m. A depth-dependent power law gain was applied to all the echograms to enhance the visibility of subsurface structures.

\section{OBSERVATIONS}

\subsection{Lake 1}

Lake 1 first appeared as $0.216 \mathrm{~km}^{2}$ of surface water in the Landsat imagery in July 2011 (Fig. 2b), before which there is no evidence of surface water ponding or deep subsurface structures (Figs 2a, f, 3a). The April 2011 radar echogram shows a thin $(<0.5 \mathrm{~m})$ new snowpack above a continuous, bright reflector inferred to be the 2010 melt season surface (Figs 2f, 3a). The 2011 echogram is nearly identical to those obtained in 2009 and 2010. A radar profile obtained in spring 2012 following the first appearance of the lake reveals a $500 \mathrm{~m}$ wide region of bright, chaotic reflectors extending from 4 to $8 \mathrm{~m}$ beneath the surface, located at the bottom of the basin and matching the aerial extent of the lake (Figs 2g, 3b). These reflectors are generally level, rather than matching the convex surface topography. While the surface surrounding the lake lowered by up to $0.8 \mathrm{~m}$ between April 2011 and April 2012, the center of the new lake rose up to $0.2 \mathrm{~m}$, so that the lake rose $1 \mathrm{~m}$ relative to the surrounding surface (Fig. 4a). Note that the flight line was $\sim 200 \mathrm{~m}$ off-center of the lake basin (Fig. 2) and, therefore, the elevation changes in the true center of the lake may have been larger.

In August 2012, during an anomalously strong melt season at high elevation on the ice sheet (Nghiem and others, 2012; Tedesco and others, 2013), the lake expanded $2.60 \mathrm{~km}^{2}$, or 

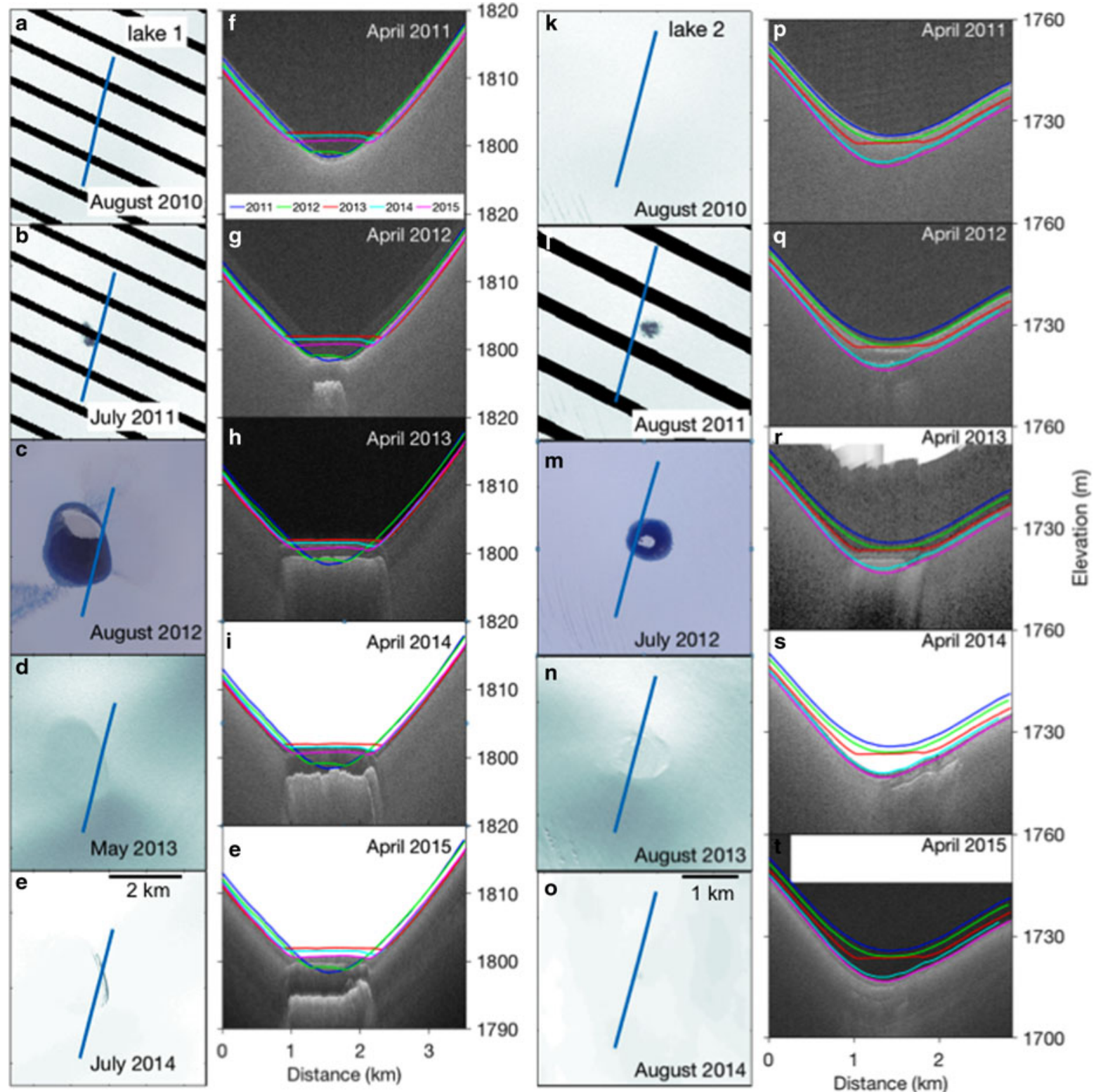

Fig. 2. Annual Operation IceBridge Survey flight lines in blue overlain on Landsat Enhanced Thematic Mapper Plus (ETM+) images, in polar stereographic projection, of $(\mathrm{a}-\mathrm{e})$ Lake 1 and $(\mathrm{k}-\mathrm{o})$ Lake 2. Plots show Kansas University snow radar echograms acquired along each flightline overlain with surface elevation acquired by the NASA Airborne Topographic Mapper, for $(\mathrm{f}-\mathrm{j})$ Lake 1 and $(\mathrm{k}-\mathrm{o})$ Lake 2, respectively. Profiles are from the southwest to northeast and ice flow is approximately east to west. Note that data from 2009 and 2010 were also examined but showed no discernable change from 2011 and, therefore, are not shown.

by nearly a factor of 5 over the previous year. An 'island' of snow or ice is visible on the north end of the lake that is of equal size and shape to the previous year's lake extent (Fig. 2c). The surface around the lake lowered by 1-2 $\mathrm{m}$ between April of 2012 and 2013, while the surface above the lake rose by $1.5 \mathrm{~m}$, so that the lake surface rose $2-3.5 \mathrm{~m}$ relative to the surrounding ice (Fig. 4a). This spatial pattern resulted in a widening and flattening of the lake basin consistent with infilling by meltwater. The April 2013 echogram (Figs $2 \mathrm{~h}, 3 \mathrm{c}$ ) records a bright, level reflector $2 \mathrm{~m}$ below the surface and four times wider than the one observed in April 2012, matching the extent of the widened basin. The reflector is 4 $m$ higher in elevation than in 2012, located at or just above the April 2012 surface elevation. No backscatter is returned below this reflector.

No clear imagery of the lake was available during the 2013 melt season and it is uncertain whether a lake formed that year. The spring 2014 aerial surveys recorded an increase in surface elevation around the lake, reaching $0.8 \mathrm{~m}$ to the north, with small changes to the south (Fig. 4a). In contrast, the lake surface lowered by up to $0.5 \mathrm{~m}$ in the center of the basin, so that the lake surface lowered by $\sim 1 \mathrm{~m}$ relative to its surroundings. The bright subsurface reflector appears similar in extent and return power as in 2013, but is less smooth and has lowered in elevation by $2.5 \mathrm{~m}$ (Figs $2 \mathrm{i}, 3 \mathrm{~d}$ ).

A lake edge reappears in the July 2014 imagery (Fig. 2e). Between spring 2014 and 2015 the lake surface lowered an additional $0.8 \mathrm{~m}$, while the surface lowered $0.4 \mathrm{~m}$ to the south of the lake edge and rose by up to $0.2 \mathrm{~m}$ to the north (Fig. 4a). The April 2015 Snow Radar echogram reveals a bright reflector $6 \mathrm{~m}$ beneath the surface, and 2-3 $\mathrm{m}$ lower in elevation than the previous year. It is similar in extent and return power to the previous year, but its northern 500 $m$ incline upward in a northeasterly direction (Figs $2 \mathrm{j}, 3 \mathrm{e}$ ). 


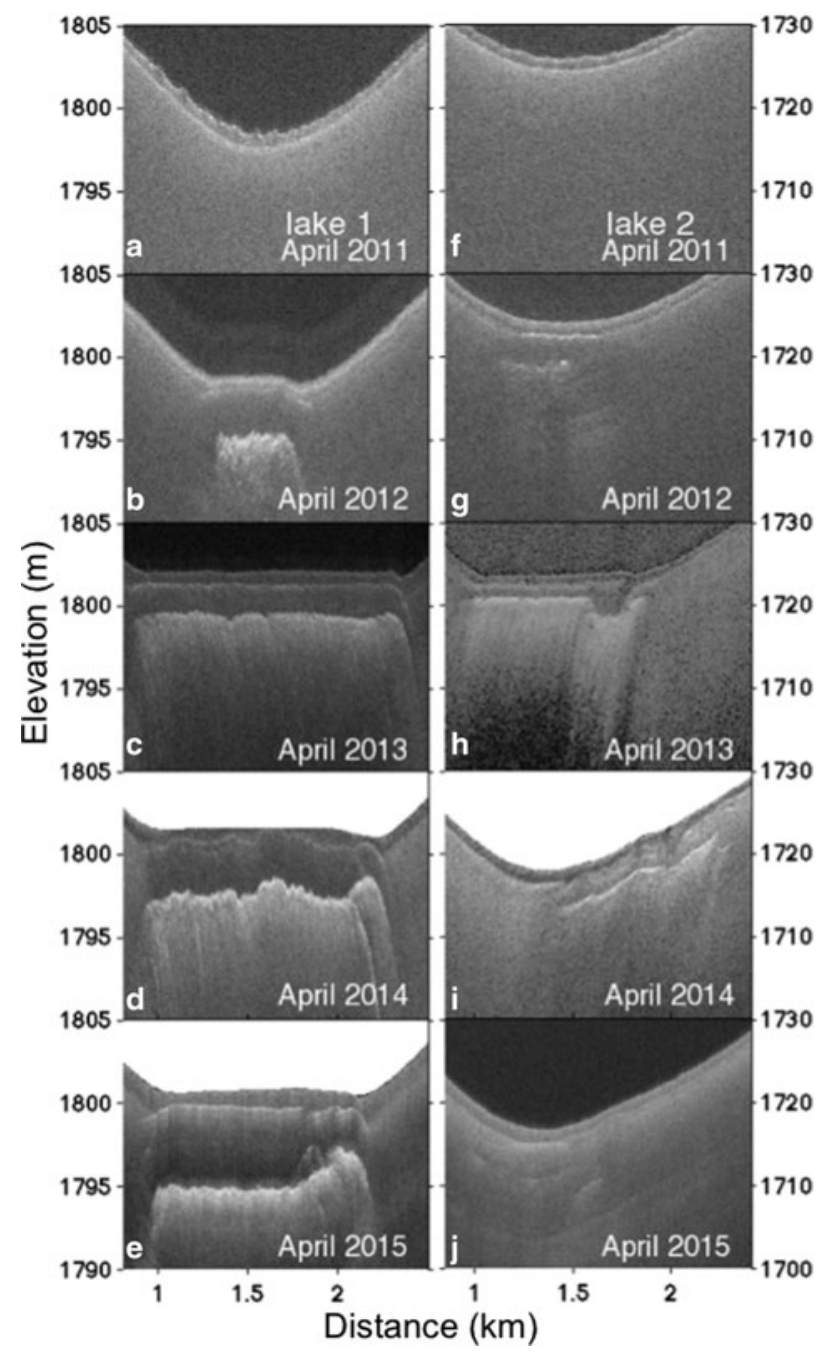

Fig. 3. Enlargements of the Kansas University snow radar echograms are shown in Fig. 2.

\subsection{Lake 2}

Lake 2 also first appeared as $0.120 \mathrm{~km}^{2}$ of surface water in August 2011 imagery, with no prior surface meltwater ponding or subsurface structures (Figs $2 k, \mathrm{l}, \mathrm{p}, 3 \mathrm{f}$ ). As with Lake 1, the April 2011 echogram only contains a thin, low backscatter snowpack atop the bright 2010 melt season surface. Surface velocities at Lake 2 are $185 \mathrm{~m} \mathrm{a}^{-1}$, or twice as fast as at Lake 1 (Joughin and others, 2010). Regionally, we expect surface lowering on the order of 1-2 $\mathrm{m} \mathrm{a}^{-1}$ due to ice flow acceleration and stretching resulting from acceleration of Jakobshavn Isbrae (Joughin and others, 2014). Potentially associated with this acceleration, crevasses appeared for the first time in Landsat imagery $1.3 \mathrm{~km}$ to the southwest of the lake in August 2010 (Fig. 5). April 2011 and 2012 altimeter surveys record an overall surface lowering of between 0.5 and $2 \mathrm{~m}$, increasing from north to south along the profile (Fig. 4b). While the 2011 and 2012 flight lines passed just west of the water surface visible in the imagery, a distinct, level, subsurface reflector appears $3 \mathrm{~m}$ below the surface in the April 2012 echogram with several scattered reflectors to $10 \mathrm{~m}$ depth (Figs 2q, 3g).

The lake was nearly six times larger in area in summer 2012 and, as Lake 1, contained a snow and ice 'island' of approximately the same size and shape as the previous year's lake surface (Fig. 2m). The spring 2013 flightline

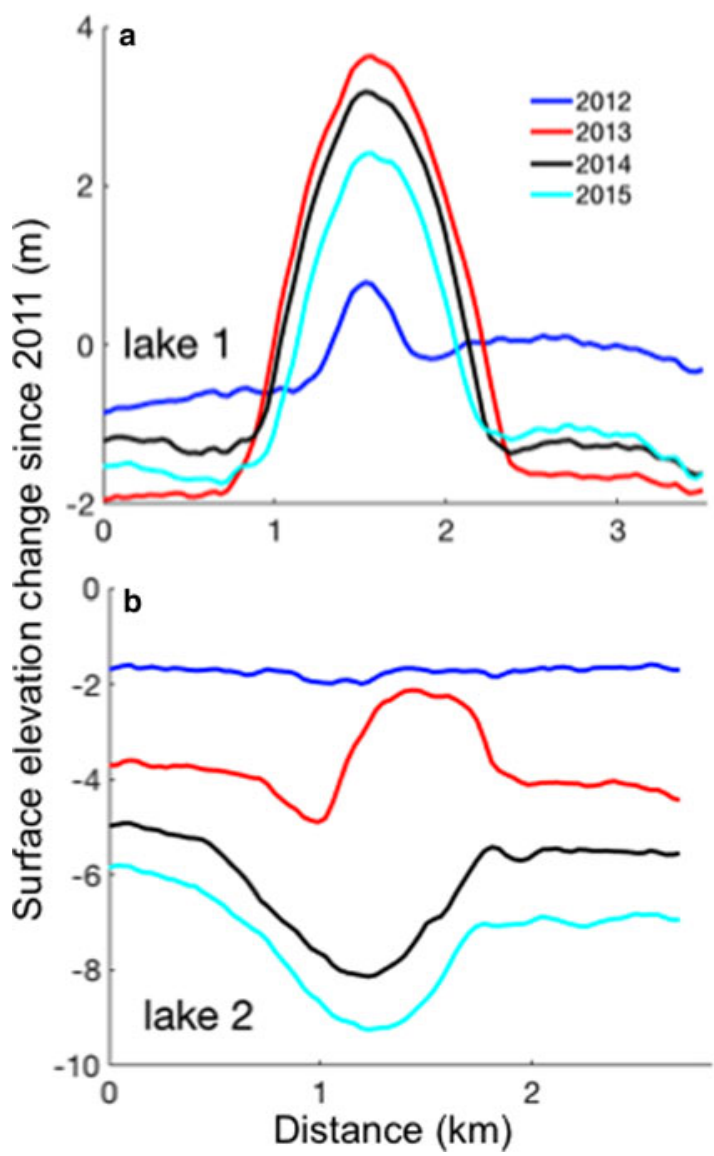

Fig. 4. Vertical surface displacement from April 2011 measured by the NASA Airborne Topographic Mapper along the flight lines shown in Fig. 2. Measurement errors are $\pm 0.2 \mathrm{~m}$.

traversed the western edge of the lake, and recorded a surface lowering of between 2 and $2.5 \mathrm{~m}$ of the area surrounding the lake basin, but only $0.2 \mathrm{~m}$ over the surveyed portion of the lake, so that the surveyed lake surface rose $2-2.5 \mathrm{~m}$ relative to the surrounding ice (Fig. 4). Consistent with this pattern of infilling, the lake basin widened and flattened. The April 2013 radar echogram again shows a

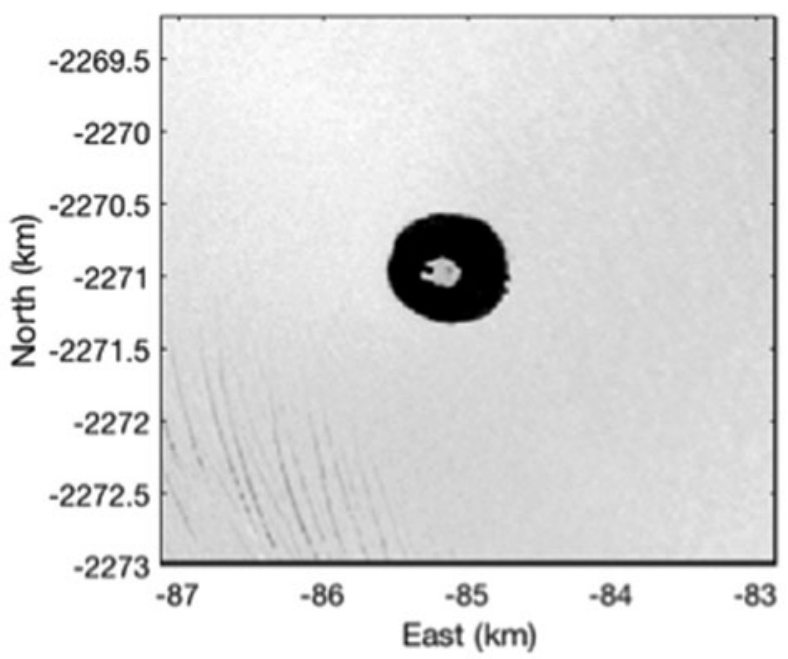

Fig. 5. Enlargement of the July 2012 Landsat image of Lake 2 (same as Fig. $2 \mathrm{~m}$ ) with a linear stretch applied to enhance the visibility of the crevasse field to the southwest of the lake. 
subsurface reflector at $\sim 2 \mathrm{~m}$ depth, at approximately the same elevation as the shallowest reflector the previous year, but substantially wider and brighter, with no backscatter beneath (Figs 2r, 3h).

While surface meltwater did not appear in the imagery during the 2013 melt season, the edges of the buried lake are clearly visible in Landsat 8 imagery acquired with a low sun-angle (Fig. 2n). The April 2014 altimeter survey shows a drop in the lake surface elevation that mirrors, in magnitude and spatial pattern, the previous rise, so that the overall lowering between 2011 and 2014 was greatest in the center of the lake, reaching $8 \mathrm{~m}$ in the middle of the surveyed portion, decreasing outward to the regional change of $4-5 \mathrm{~m}$ (Fig. 4b). The bright, horizontal subsurface reflector visible the previous year is no longer present in the 2014 echogram, with the only clearly visible structure a bright, surface parallel reflector on the North side of the lake at 4.6 m depth (Figs 2s, 3i). Also in contrast to the previous years survey, there appears to be backscatter from up to $10 \mathrm{~m}$ below the surface.

The lake's darkened surface appears faintly in an OLI image from August 2014 (Fig. 20) and is similar in size and shape to the previous year. The spring 2015 aerial survey observed near uniform lowering of $1.2 \mathrm{~m}$ across the profile (Fig. 4b). A $300 \mathrm{~m}$ long, bright reflector is observed $2 \mathrm{~m}$ beneath the surface (Figs 2t, 3j). The level reflector underlies a convex surface. Between 2 and $4 \mathrm{~m}$ beneath the flat reflector are several short scattered reflectors that are parallel to the surface.

\subsection{MAR climatology}

We use estimates of meltwater and snowfall from the Modèle Atmosphérique Régional (MAR) regional climate model version 3.5 for the period 1948-2015. The $25 \mathrm{~km}$ spatial resolution model comprises an atmospheric model, developed by Gallée and Schayes (1994), coupled to a 1-D Soil Ice Snow Vegetation Atmosphere Transfer (SISVAT) surface model, described in De Ridder and Gallée (1998). Within the atmospheric component, there are 25 levels over Greenland (Tedesco and others, 2016). To account for melt, percolation and refreeze processes, a multi-layer snow/ice model CROCUS, from Centre $d^{\prime}$ Etudes de la Neige has been incorporated into MAR (Brun and others, 1992; Fettweis and others, 2007). We obtain time series' of meltwater production and snowfall accumulation at the location of each lake through 3-D linear interpolation from the model grid. Since the estimates are similar for each lake, the averages of the two time series are presented in Fig. 6.

A regional increase in meltwater production since 2000 was concurrent with an increase in warming (Fig. 6a), with five of the eight highest records of melt within the 19482015 MAR record occurring after the year 2000. The 2011 melt season, in which the lakes first appeared, was near average in melt production, preceded and followed by the second and first highest melt years, respectively, in the 68year record. MAR estimates total snow accumulation for the two lakes in 2009 and 2011 as two of the four lowest annual snowfall records within the 1948-2015 period (Fig. 6b). These record snowfall lows surround a year of near average snowfall in 2010.

\section{DISCUSSION}

Repeated airborne altimeter and ice-penetrating radar surveys capture the formation and evolution of two lakes

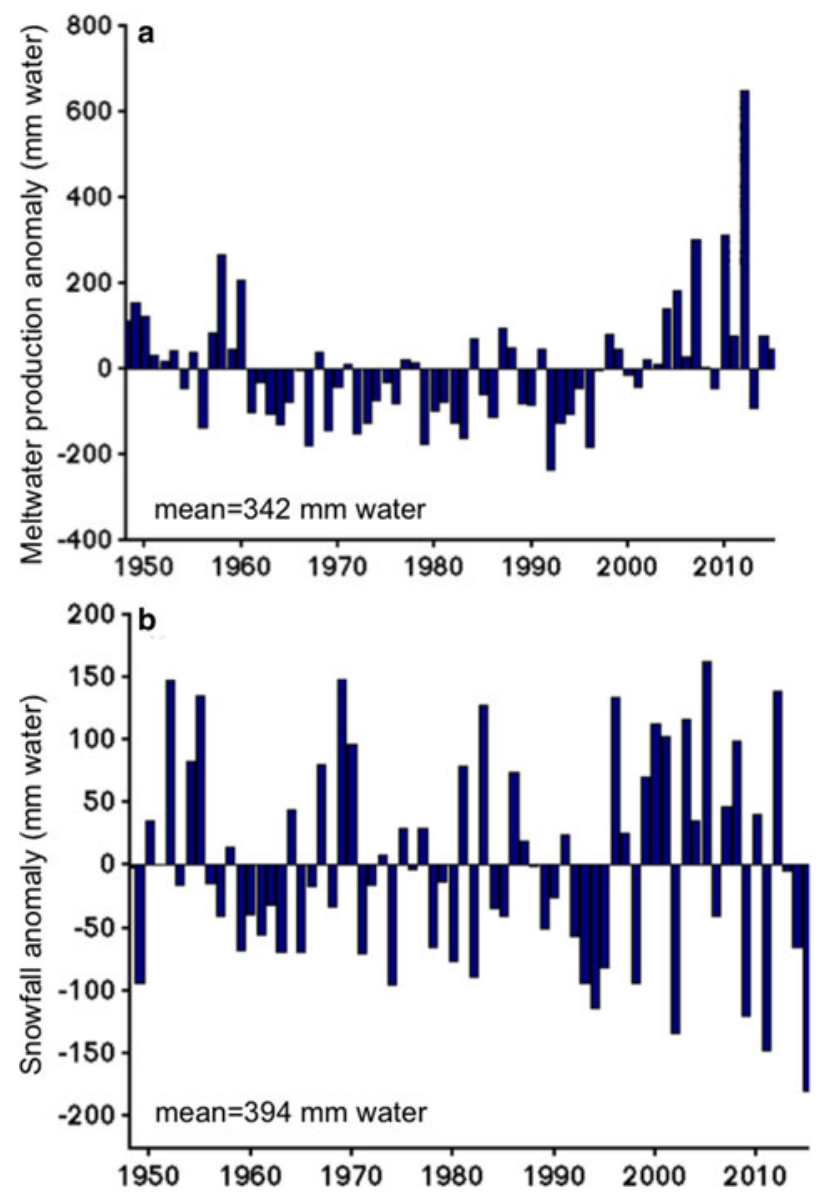

Fig. 6. Anomalies from the 1948 to 2015 means in annual (a) meltwater production and (b) snowfall at Lakes 1 and 2 estimated by the Modèle Atmosphérique Régional (MAR) regional climate model version 3.5. The average of the estimates for the lake locations are shown because each lake had similar variability.

within the percolation zone of the Greenland ice sheet. The observations are consistent with the hypothesis that anomalously high melt leads to reduced permeability of near-surface firn, run-off and ponding within topographic depressions. Despite similar patterns of initial formation at the two lakes, the observations reveal contrasting behaviors that yield insight into lake development and persistence. In the following sections we compare and contrast the formation and evolution of the two lakes.

The lakes formed in a year of anomalously low accumulation (2011), preceded by over a decade of increasing surface melt, and especially high melt in 2010. These conditions led to increased firn ice content and reduced permeability (Mikkelsen and others, 2016; Machguth and others, 2016), which would reduce the amount of pore space available in the underlying firn for meltwater infiltration and cause lakes to form.

There are no visible structures beneath the lake basins and their surrounding regions in the spring 2010 (not shown) and spring 2011 echograms, indicating that pre-existing ice layers were too thin or of too low a density contrast to resolve. Subsurface reflectors are first observed in the spring radar echograms for both lakes following the 2011 melt season when the lakes first appeared, extending up to $10 \mathrm{~m}$ below the surface. Since 2011 was not an exceptional melt year, it is unclear what would cause the appearance of these layers. The correspondence between the layers and the 
first appearance of surface water ponding suggests a change in conditions toward decreased permeability. One possibility is that the anomalously low accumulation in 2011 resulted in a thin, new snowpack with less storage capacity for meltwater. More meltwater would then reach the low-permeability 2010 melt season surface and be routed horizontally toward the topographic low of the lake basins, causing ponding and deep infiltration there, as indicated by the deep subsurface structures in the April 2012 echograms.

Both lakes grew substantially during the extreme melt season of 2012 and a bright, level reflector is found $2 \mathrm{~m}$ below the surface reflector in both April 2013 echograms. No backscatter is returned from beneath this layer. Since MAR predicts $1.6 \mathrm{~m}$ of new snowfall at both lakes between September 2012 and April 2013, the depth of the bright reflector is a few decimeters below the expected 2012 melt season surface. We therefore interpret this reflector to be the boundary between lake surface ice and liquid water below. This interpretation is consistent with Koenig and others (2015), which first documented perennial liquid water in buried supraglacial lakes based on the attenuation of backscatter across multiple radio frequencies. This results from the order of magnitude higher fraction of reflected power at the boundary between ice and liquid water, relative to that between ice and snow (Navarro and Eisen, 2010).

Our data reveal a sharp transition in firn structure at the lake edges. The bright, level, radar-opaque reflector terminates abruptly where the surface slope begins to increase, with little or no change in the echograms of the firn surrounding the lake. This contrasts with the expectation that increased meltwater throughput and refreezing would result in extensive ice layer formation, as described by De la Peña and others (2015), Mikkelsen and others (2016) and Machguth and others (2016). We would then also expect an increase in the quantity of ice approaching the lake, as the total throughput of meltwater increases downslope. Either such structures cannot be resolved, or water is efficiently drained at or near the surface to the lake, so that little is refrozen in the surrounding firn. Thus, the sharp transition radio echo structure between the lake and the surrounding firn suggest that the lake formed over an ice lens within the basin low.

Both lakes also contained an ice island in 2012 that match the size and shape of the 2011 lake surface. Such features are common in supraglacial lakes as seen in satellite imagery. We hypothesize that the island consists of the previous year's refrozen lake water, topped by new snow. The refrozen meltwater in the lake would have a lower permeability than the firn around and beneath it, so that the next season's melt would drain into the interface between the refrozen meltwater and the firn, where it would pond, causing the previous year's refrozen lake to float atop it.

While initial development and expansion of the lakes were similar, the evolution of the lakes diverged. Following 2012's anomalous melting, 2013 had below average melt and near average snowfall, while 2014 had slightly higher than average melting and below normal snowfall. During this period the center of Lake 1 's surface dropped $\sim 0.5 \mathrm{~m} \mathrm{a}^{-1}$ relative to the surrounding ice sheet. At the same time, the bright, radio opaque reflector, interpreted to be the lake ice/water interface, lowered at rate of $2 \mathrm{~m} \mathrm{a}^{-1}$. Since the lake sits in a closed basin with no evidence of crevassing, we assume no horizontal transport of mass from the lake.
Further, we assume that accumulation and densification of new snow and vertical strain of the ice column at the lake was the same as its surroundings. Thus, the relative lowering of the lake surface would be due to drainage of the lake into the pore space of the underlying firn, minus expansion due to refreezing of lake water. Lowering of the ice/water interface would be due to lake drainage and refreezing of the lake surface. If all of the $1.5 \mathrm{~m} \mathrm{a}^{-1}$ difference in lowering between the ice/water interface and the lake surface was due to refreezing, the expansion would offset densification and drainage by $\sim 0.15 \mathrm{~m}$. Refreezing should also occur at the lake bottom, but this should be substantially slower due to an increasing thermal gradient during winter. Therefore, we interpret the relative lowering of the lake surface to indicate drainage into the underlying firn at a rate greater than but close to $0.5 \mathrm{~m} \mathrm{a}^{-1}$.

In contrast, the surface above Lake 2 fell $5 \mathrm{~m}$ relative to the surrounding ice sheet between April 2013 and April 2014, with the basin returning to its parabolic, pre-2012 shape and the radar-opaque subsurface reflector disappearing completely. Such a rapid drop in the surface and change in echogram character could only be accomplished through drainage of the lake. The uniform surface lowering of Lake 2 and its surrounds between 2014 and 2015, and the fact that no surface water was evident in the summer of 2014, suggests an efficient drainage system had formed. While rapid lake drainage is well documented in the ablation zone, where water drains either through overtopping or through connections to the ice bed, this is, to our knowledge, the first observed occurrence of rapid lake drainage in the percolation zone. The lake was not large enough to penetrate the $1.5 \mathrm{~km}$ of underlying ice and no surficial drainage features, such as channels, are present in the imagery. Drainage, therefore, must have been accommodated within the underlying firn and ice column. The annual resolution of our dataset is too coarse to determine whether drainage occurred suddenly, such as through a connection to the nearby crevasse field, or slowly to the underlying firn through weaknesses in the aquitard (i.e. low permeability ice lenses) upon which the lake formed. In either case, however, drainage would be enabled by the horizontal ice stretching occurring in response to acceleration of Jakobshavn Isbrae. Stretching would likely extend crevasses, as well as open fractures in near-surface ice layers.

\section{CONCLUSIONS}

We use repeat airborne altimetry and ice-penetrating radar surveys to investigate the evolution of two, newly formed supraglacial lakes in the percolation of the Greenland ice sheet. Our observations suggest that the lakes formed initially due to local, near-surface run-off within an anomalously thin snowpack above a low-permeability layer of infiltration ice formed during the previous, anomalously high melt seasons.

Both lakes grew substantially and retained subsurface liquid water following the record melt season of 2012. During the low melt seasons of the 2013 and 2014, the surface of Lake 1, located above the relatively stable land-terminating margin of southwest Greenland, lowered slowly due to drainage into the underlying firn pore space. In contrast, the surface of Lake 2, located in accelerating ice above Jakobshavn Isbrae, dropped $5 \mathrm{~m}$ in a single year, indicating drainage into the underlying firn. 
Despite the substantial changes in subsurface hydrology observed in the radar echograms over the lakes, there is little or no observable change observable in radar returns of the surrounding ice sheet. This implies efficient run-off in the near surface firn, likely along low-permeability ice layers formed during the previous melt seasons, supporting the hypothesis that more severe melt events may prevent subsequent infiltration. This mechanism would act to increase run-off from higher on the ice sheet, reducing ice-sheet mass balance. The magnitude of this contribution will depend on the amount of melt and the existing hydrological character of the firn. Also important will be the fine-scale surface topography of the ice sheet, as basins will enable storage of meltwater within lakes, potentially reducing the amount runoff. Thus, climate and snowpack modeling combined with accurate, high-resolution ice surface topography will be needed to estimate future run-off from the percolation zone.

\section{ACKNOWLEDGEMENTS}

This work was supported by US National Aeronautics and Space Administration grant NNX11AR47G to I.M.H. The authors acknowledge the tremendous efforts of the Operation IceBridge instrument and flight teams to collect the data used in this study. The authors thank the scientific editor and anonymous reviewer for providing valuable feedback to improve the manuscript.

\section{REFERENCES}

Box JE (2013) Greenland ice sheet mass balance reconstruction. Part II: surface mass balance (1840-2010). J. Clim., 26(18), 6974-6989

Brun E, David P, Sudul M and Brunot G (1992) A numerical model to simulate snow-cover stratigraphy for operational avalanche forecasting. J. Glac., 38(128), 13-22

De la Peña $S$ and 8 others (2015) Changes in the firn structure of the Greenland Ice Sheet caused by recent warming. Cryosphere Discuss., 9(1), 541-565 (doi: 10.5194/tcd-9-541-2015)

De Ridder K and Gallée H (1998) Land surface-induced regional climate change in Southern Israel. J. Appl. Meteorol., 37(11), 1470-1485

Fettweis X (2007) Reconstruction of the 1979-2006 Greenland Ice Sheet surface mass balance using the regional climate model MAR. Cryosphere, 1, 21-40

Fitzpatrick AAW and 9 others (2014) A decade (2002-2012) of supraglacial lake volume estimates across Russell Glacier, West Greenland. Cryosphere, 8(1), 107-121 (doi: 10.5194/tc-8-107-2014)

Gallée H and Schayes G (1994) Development of a 3-dimensional meso-gamma primitive equation model - katabatic winds simulation in the area of Terra-Nova Bay, Antarctica. Mon. Weather Rev., 122(4), 671-685 (doi: 10.1175/1520-0493(1994) $122<0671: D O A T D M>2.0 . C O ; 2)$
Harper J, Humphrey N, Pfeffer WT, Brown J and Fettweis X (2012) Greenland ice-sheet contribution to sea-level rise buffered by meltwater storage in firn. Nature, 491(7423), 240-243 (doi: 10.1038/nature11566)

Howat IM, de la Pena S, van Angelen JH, Lenaerts JTM and van den Broeke MR (2013) Expansion of meltwater lakes on the Greenland Ice Sheet. Cryosphere, 7(1), 201-204 (doi: 10.5194/ tc-7-201-2013)

Joughin I, Smith BE, Howat IM, Scambos T and Moon T (2010) Greenland flow variability from ice-sheet-wide velocity mapping. J. Glaciol., 56(197), 415-430

Joughin I, Smith BE, Shean DE and Floricioiu D (2014) Brief communication: further summer speedup of Jakobshavn Isbrae. Cryosphere, 8(1), 209-214 (doi: 10.5194/tc-8-209-2014)

Koenig LS and 11 others (2015) Wintertime storage of water in buried supraglacial lakes across the Greenland Ice Sheet. Cryosphere, 9(4), 1333-1342 (doi: 10.5194/tc-9-1333-2015)

Krabill WB (2010, updated 2015) Icebridge ATM L2 icessn elevation, slope, and roughness, version 2. 2011-2014. Boulder, Colorado, USA. http://dx.doi.org.proxy.lib.ohio-state. edu/10.5067/CPRXXK3F39RV

Leuschen $C$ and 6 others (2014) Icebridge snow radar L1B geolocated radar echo strength profiles, version 2, 2014. Boulder, Colorado, USA: NASA DAAC at the National Snow and Ice Data Center. http://dx.doi.org.proxy.lib.ohio-state.edu/10.5067/ FAZTWP500V70

Machguth $\mathrm{H}$ and 9 others (2016) Greenland meltwater storage in firn limited by near-surface ice formation. Nat. Clim. Chang., 6(4), 390-393 (doi: 10.1038/NCLIMATE2899)

Mikkelsen $\mathrm{AB}$ and 9 others (2016) Extraordinary runoff from the Greenland ice sheet in 2012 amplified by hypsometry and depleted firn retention. Cryosphere, 10(3), 1147-1159 (doi: 10.5194/tc-10-1147-2016)

Navarro F and Eisen O (2010) Ground penetrating radar. In Pellikka P and Rees WG, eds. Remote sensing of glaciers - techniques for topographic, spatial and thematic mapping. CRC Press, Leiden, 195-229

Nghiem SV and 8 others (2012) The extreme melt across the Greenland ice sheet in 2012. Geophys. Res. Lett., 39, L20502 (doi: 10.1029/2012GL053611)

Rodriguez-Morales F and 17 others (2014) Advanced multifrequency radar instrumentation for polar research. IEEE Trans. Geosci. Remote Sens., 52(5), 2824-2842 (doi: 10.1109/ TGRS.2013.2266415)

Tedesco M and 6 others (2013) Evidence and analysis of 2012 Greenland records from spaceborne observations, a regional climate model and reanalysis data. Cryosphere, 7(2), 615-630 (doi: 10.5194/tc-7-615-2013)

Tedesco M and 5 others (2016) The darkening of the Greenland ice sheet: trends, drivers, and projections (1981-2100). Cryosphere, 10(2), 477-496 (doi: 10.5194/tc-10-477-2016)

van Angelen JH, van den Broeke MR, Wouters B and Lenaerts JTM (2014) Contemporary (1960-2012) evolution of the climate and surface mass balance of the Greenland Ice Sheet. Surv. Geophys., 35(5), 1155-1174 (doi: 10.1007/s10712-013-9261-z) 